\title{
Comment
}

\section{US - Countervailing Duty Investigation of DRAMS}

\section{Prepared for the ALI Project on the Case Law of the WTO}

\author{
THOMAS J. PRUSA \\ Department of Economics, New Jersey Hall, 75 Hamilton Street, Rutgers University, \\ New Brunswick, NJ, 08901-1248. Email: prusa@econ.rutgers.edu
}

\begin{abstract}
There are two compelling issues involved in US - Countervailing Duty Investigation of DRAMS. First, there is the question of whether creditors were 'entrusted or directed' to make financial contributions to Hynix, a large South Korean DRAM producer. This was the main topic addressed by the Appellate Body $(\mathrm{AB})$ and is the focus of the François-Palmeter paper. Second, there is there is the question of injury assessment and nonattribution. Because the US did not appeal the Panel's decision, this aspect of the WTO dispute was not considered by the $\mathrm{AB}$.
\end{abstract}

\section{Background}

In 1995, over $\$ 40$ billion of DRAMs were sold worldwide. For the next seven years the DRAM market languished with sales revenue flat or declining year after year. In 2001, less than $\$ 10$ billion of DRAMs were sold, even though the standard DRAM chip sold increased in capacity from just four megabytes (MB) to $256 \mathrm{MB}$. Prices were lower than industry experts predicted, and all DRAM manufacturers were losing money. As a result of this demand slump, by mid-2001 many DRAM manufacturers were on the brink of bankruptcy. Hynix, a large South Korean DRAM manufacturer, was perhaps the entity most precariously teetering on the ledge. Hynix, formerly a division of the giant Korean Hyundai Group, was an important part of the Korean economy, accounting for almost $4 \%$ of all Korean exports in 2000. Hynix was highly leveraged with billions in outstanding loans from both the Korean government (much of it dating back to when it was part of the Hyundai Group) and private creditors from around the world.

In 2001 creditors of Hynix agreed to a $\$ 7$ billion bailout; the financing was comprised of new additional credit and a $\$ 2$ billion debt/equity swap. 
Participating creditors included government-owned banks, banks partially owned (but arguably controlled) by the Korean government, and a number of foreign banks.

Despite the promised bailout, Hynix remained the subject of numerous rumors of mergers with other DRAM manufacturers throughout 2001. The conventional wisdom was that there was excess DRAM capacity in the market and that Hynix was an ideal target for consolidation and rationalization. In early 2002, US-based Micron Technology Inc. offered \$3.4 billion for Hynix's memory-chip business (the core of Hynix's business). The offer was rejected by Hynix's board in May 2002. When its takeover offer was spurned, Micron formally requested the countervailing-duty investigation with which it had been threatening Hynix. In 2003, the US determined that the bailout constituted a subsidy to Hynix and that the subsidized exports were the cause of material injury. The Korean government appealed the decision to the WTO. The panel ruled in favor of Korea on the vast majority of its claims, finding both the US's injury and subsidy calculations to be inconsistent with WTO rules. The US did not appeal the injury decision but requested the $\mathrm{AB}$ review the subsidy issues.

\section{The issue of subsidy}

As discussed by François and Palmeter, the key question before the $\mathrm{AB}$ was the whether creditors were 'entrusted or directed' by the Korean government to make financial contributions to Hynix. François and Palmeter discuss the idea that a series of events, taken together, can be construed to satisfy the 'entrusted or directed' standard even though any single incident is not definitive. In effect, the sum of the parts is greater than the whole.

One example of an event in a sequence of questionable acts is the allegation that banks waived loan ceilings to Hynix. Taken at face value, waiving the loan limit suggests that the government was going beyond standard practice to keep Hynix financially viable. This issue is incriminating evidence of special treatment. By itself, it was not evidence of a subsidy, but as part of a large number of other 'unusual' events, François and Palmeter argue that it can support a determination of government control.

A more subtle issue is whether the loan limits were truly waived. In particular, a key question not discussed by François and Palmeter is whether the preexisting loans were made to Hynix or to the Greater Hyundai Group and partially inherited by Hynix. If the latter, the US might argue that the loan ceiling was breached, while Korea might argue that additional loans to Hynix were below the ceiling (because it discounts the original Hyundai loans). The view that the sequence is demonstrative depends not just on the nature of each event, but also on the probative value of each claim. Without a better understanding of the underlying events, it is almost impossible to know whether the sequence is telling. 
My own view is that, while the sequence discussion is interesting, the authors should also have tackled a more basic issue: is it likely that the government of Korea's intervention changed the market outcome? If so, then it is likely that the subsidy has affected the market in a way not desired by the WTO: this is the crux of the US's argument.

Korea's argument stressed the ex post outcome. That is, Korea argued that the foreign banks offered Hynix interest rates comparable to those offered to other companies at the same time period. According to Korea, there was no suasion, as foreign banks were treating Hynix no differently than they were treating other commercial clients. But the observed market outcome does not tell us about what the outcome would have been without government intervention.

To be a bit more precise, suppose for a moment that the market interest rate is $i^{M}$ and that the return on a loan to Hynix is $i^{H}$. For argument's sake, let's suppose that without government intervention $i^{H}<i^{M}$; thus, without government intervention, banks will not provide the loan package. Now, let's also suppose that with government intervention $i^{H}=i^{M}$; and thus banks provide the loan package.

Korea argues that the fact that $i^{H}=i^{M}$ is an indication that the banks did not have 'their arms twisted' to make the Hynix loans; after all, they receive the same return as on other comparable loans. However, if the above scenario is true, the fact that we observe $i^{H}=i^{M}$ tells us nothing about what the return would have been without government involvement (assuming, that is, that there really was intervention).

\section{The issue of injury}

The US's injury determination suffered from many of the same shortcomings that have been discussed in other disputes. Two key flaws were noted by the Panel. First, the US did not separate the effects of Hynix DRAMs (i.e., the product subject to the investigation) from Samsung DRAMs (i.e., product not subject to the investigation). Second, the US did not properly assess the overall condition of the domestic industry in light of the weak market demand. In effect, Korea argued that Hynix was blamed for injury caused by Samsung (which accounted for the bulk of Korean DRAMs shipped to the US) and by weak demand. As it has done in the past, the US could not present any formal evidence that it had disentangled the various factors. The agency making injury determinations in the US, the US International Trade Commission (USITC), is reluctant to fully embrace economic inference and econometrics, as doing so would entail a loss of discretion.

The US did not appeal the injury analysis to the $\mathrm{AB}$ and instead requested the USITC to reconsider its determination in light of the Panel's comments. Always reluctant to acknowledge shortcomings in its analysis, the USITC simply reaffirmed its prior decision without any substantive changes in its analysis. 


\section{Postscript}

This case highlights shortcomings of the WTO appeals process. On the one hand, the AB was unhappy with certain aspects of the Panel's determination and could not support the Panel's conclusions as written. On the other hand, the AB did not embrace the US position, either. Thus, what was really needed was the ability for the $\mathrm{AB}$ to remand the case back to the Panel. The need for a remand procedure is further highlighted by the seeming refusal of the USITC to incorporate the Panel's injury criticisms. Intransigence is hardly the basis for an appeal, but the unwillingness of the USITC to adjust its injury analysis is frustrating for foreign parties.

While Korea could have again filed an appeal to the WTO, two developments apparently changed the Korean government's calculus. First, a vast worldwide price-fixing scheme came to light in December 2003. As noted above, the Hynix bankruptcy crisis was caused primarily by persistent weak DRAM prices. Apparently, prices would have been even weaker had not all the major DRAM manufacturers regularly met to set prices over a three-year period. In light of the embarrassing disclosure, the Korean government may not have had the stomach for continuing its efforts on behalf of Hynix. Second, the duties on Hynix accelerated Hynix's efforts to build facilities in China. By the time the WTO AB made its decision, the US CVD orders were effectively moot, as Hynix either shipped the chips to China for processing or shipped DRAMs produced in its China facility to the US. Thus, there was substantially less commercial interest in the outcome by 2005 . 